\title{
Genetic control and evolutionary potential of a constitutive resistance mechanism against the spruce budworm (Choristoneura fumiferana) in white spruce (Picea glauca)
}

\author{
Claudia Méndez-Espinoza ${ }^{1,2,3} \cdot$ Geneviève J. Parent $\mathbb{1}^{1,2,4} \cdot$ Patrick Lenz $^{5,6} \cdot$ André Rainville $^{7} \cdot$ Laurence Tremblay $^{7}$. \\ Greg Adams ${ }^{8} \cdot$ Andrew McCartney $^{8} \cdot$ Éric Bauce $^{1} \cdot$ John MacKay ${ }^{1,2,4}$
}

Received: 19 July 2017 / Revised: 5 December 2017 / Accepted: 11 December 2017 / Published online: 17 February 2018

(c) The Genetics Society 2018

\begin{abstract}
Insect herbivory may drive evolution by selecting for trees with heritable resistance against defoliation. The spruce budworm (Choristoneura fumiferana, $\mathrm{SBW}$ ) is a highly damaging forest insect pest that can affect population structure of white spruce (Picea glauca) in North America. Resistance against SBW was recently described in white spruce and was linked to three constitutive resistance biomarkers: the phenolic compounds piceol and pungenol, and expression of a beta-glucosidase encoding gene (PgBglu-1). We investigated the phenotypic variability and heritability of these resistance biomarkers and of picein, the precursor of piceol, in the foliage of 874 trees belonging to 33 full-sib families and 71 clonal lines under evaluation in seven field locations in Eastern Canada. We aimed to (i) determine their genetic control, (ii) estimate the genetic and phenotypic correlations among defense biomarkers, and (iii) determine whether their constitutive levels are associated with detrimental trade-offs on growth. Quantitative genetics analyses indicated that all four traits are moderately to highly heritable. The full-sib and clonal analyses showed that additive and non-additive genetic effects play major and minor roles, respectively. Positive genetic and phenotypic correlations between resistance biomarkers and primary growth indicated that there is no trade-off between total height and height increment and resistance traits, contradicting the GDBH (Growth Differentiation Balance Hypothesis). Our findings about the predominant additive genetic basis of the resistance biomarkers show that adaptive evolution of white spruce natural populations to resist to SBW is possible and that potentially important gains could also be expected from artificial selection.
\end{abstract}

Electronic supplementary material The online version of this article (https://doi.org/10.1038/s41437-018-0061-6) contains supplementary material, which is available to authorized users.

Claudia Méndez-Espinoza

clyame@hotmail.com

1 Centre d'étude de la forêt, Département des sciences du bois et de la forêt, Université Laval, Québec, QC G1V 0A6, Canada

2 Institut de Biologie Intégrative et des Systèmes, Université Laval, Québec, QC G1V 0A6, Canada

3 Instituto Nacional de Investigaciones Forestales, Agrícolas y Pecuarias, Centro Nacional de Investigación Disciplinaria en Conservación y Mejoramiento de Ecosistemas Forestales Av. Progreso 5, Barrio de Santa Catarina 04010 Ciudad de México CDMX Mexico

\section{Introduction}

Plant resistance may evolve in response to herbivory (Strauss and Agrawal 1999). The evolutionary potential describes the capacity to evolve as a feedback to changing environments and selective pressure (Harrisson et al. 2014), and some of the factors influencing the evolutionary

4 Department of Plant Sciences, University of Oxford, Oxford 0X1 3RB, UK

5 Canadian Wood Fibre Center, Natural Resources Canada, Québec, QC G1V 4C7, Canada

6 Canada Research Chair in Forest Genomics, Université Laval, Québec, QC G1V 0A6, Canada

7 Ministère des Forêts, de la Faune et des Parcs, Québec QC G2K 0G9 Canada

8 J.D. Irving, Limited, Saint John, NB E4G 2V5, Canada 
potential of plant resistance traits are the genetic variation, heritability, and the correlation among defensive characters and costs of resistance (Lande and Arnold 1983; Geber and Griffen 2003). Therefore, knowledge of these parameters is fundamental for understanding the possible outcomes resulting from host-insect interaction such as counterresistance, ecological costs of resistance and multi-trophic level effects (Rausher 2001; Strauss et al. 2002; Harvey et al. 2003).

The present study examines resistance against the spruce budworm (SBW) (Choristoneura fumiferana), a lepidopteran native to North America that has long influenced the forest stand dynamics and productivity of spruces and balsam fir. Epidemic periods of the SBW have been recorded for more than three centuries in eastern regions of Canada and the USA and have recently occurred at intervals of 25-38 years (Jardon et al. 2003). The destructive capacity of the insect is such that during the peak of the last outbreak (1965-1992), defoliation by SBW destroyed as much as $64-91 \%$ of the annual biomass production in the most severely affected areas (Gray et al. 2000; Volney and Fleming 2007).

Naturally occurring resistance to SBW attack was recently reported for the first time (Daoust et al. 2010) and has been linked to the content of the acetophenones piceol and pungenol in the foliage of white spruce (Picea glauca (Moench) Voss) (Delvas et al. 2011). The effects of piceol and pungenol on SBW were studied in laboratory rearing conditions and caused a decreased survival of larvae, reduced pupal mass, and delayed development of insects (Delvas et al. 2011). The Pg/glu- 1 gene encodes a $\beta$-glucosidase enzyme responsible for the release of piceol and pungenol from the acetophenone glucosides picein and pungenin, respectively (Mageroy et al. 2014).

More recently, large differences in the constitutive level of acetophenones and Pgßglu-1 gene expression were detected between $P$. glauca individuals from different geographic origins (Parent et al. 2017). The authors monitored the dynamics of the defense biomarkers over the course of a growing season and compared genotypes from throughout eastern Canada, spanning from eastern Ontario to Nova Scotia. The pattern was positively correlated with the intensity of past SBW outbreaks, suggesting that the traits are under positive selection in natural populations (Parent et al. 2017); a process that increases the frequency of advantageous heritable characters in a population.

Heritability is defined as the proportion of the total phenotypical variation of a trait that is due to additive effects (narrow-sense heritability) or both additive and nonadditive genetic factors such as epistasis or dominance (broad-sense heritability) (Visscher et al. 2008). Narrowsense heritability estimates are considered an indicator of evolutionary potential in outbreeding organisms such as most conifers (Geber and Griffen 2003; Charmantier and Garant 2005; Hansen et al. 2011). Therefore, it may be used to predict the adaptability of trees species to biotic agents.

However, a potential drawback of resistance is that it may be associated with trade-offs affecting other physiological traits including growth because carbon and energy resources used for the synthesis of chemical defenses may limit the availability for other plant functions such as the formation of new tissues, growth or reproduction (Obeso 2002; Sampedro et al. 2011; Walters 2011). Various hypotheses attempt to explain patterns of intraspecific tradeoffs between plant defense mechanisms and growth along different environmental conditions; however, they all contain intrinsic contradictions that remain to be resolved (Hahn and Maron 2016). Two of the main theories supporting the existence of trade-offs are the GrowthDifferentiation Balance Hypothesis (GDBH) and the Optimal Defense Theory (ODT). The GDBH relies on the general idea that there is a physiological trade-off between growth and differentiation processes (Herms and Mattson 1992). The ODT postulates that defenses are mainly directed to plant structures with an elevated risk of herbivory and fitness value, where they are more likely to be constitutive and thus costly (Rhoades 1979). Uncovering the phenotypic and genetic relationships between the resistance biomarkers and growth would be a first step in assessing the potential trade-offs.

The overall goal of the present study is to investigate the heredity of defense traits against SBW in white spruce including constitutive acetophenone levels and the expression of the $P g \beta g l u-1$ gene. Our specific objectives were to: (1) determine their phenotypic variability and genetic control in a set of progeny and clonal trials set up in different ecological regions; (2) estimate the genetic and phenotypic inter-trait correlations, and (3) evaluate whether the resistance against the SBW is associated with a detrimental trade-off on white spruce growth. The primary data for this study were four traits, which are the foliar levels of three acetophenone compounds, picein, piceol, and pungenol, as well as the expression of the Pg/glu-1 gene. The three later of these traits have been associated with resistance against SBW in white spruce (Mageroy et al. 2014) and are referred to hereafter as SBW resistance biomarkers. Whenever we refer to all four traits, we call them defense biomarkers.

We analyzed both full-sib progeny and clonal lines to gain insights into the nature of the genetic control underpinning these defensive biomarkers. Our findings on genetic control and growth trade-offs shed light into the evolutionary potential of the traits and suggest that the resistance biomarkers could be efficiently manipulated through genetic selection and breeding. 


\section{Materials and methods}

\section{Plant material}

Two types of $P$. glauca genetic trials were evaluated: a fullsib progeny test and two clonal tests, which were set up in contrasting ecological domains in the provinces of Quebec and New Brunswick, Canada. They are part of two independent genetic improvement programs of the Ministère des Forêts, de la Faune et des Parcs of Quebec (MFFP) and J.D. Irving, Limited (JDI). None of the trials have experienced any observable SBW infestation. Both breeding programs pursue the improvement of stem growth and straightness, volume and wood physical properties while keeping a wide genetic pool for pest resistance (Gernandt et al. 2011). To perform the parental selection, the JDI program specially focused on tree health during the peak of the last budworm epidemic.

In total, we evaluated 33 families for the progeny tests and 71 clonal lines. The full-sib progeny trial was established on two sites in 2007: (1) Grandes-Piles in the sugar maple-yellow birch ecological domain and (2) Normandin in the balsam fir-yellow birch ecological domain (Saucier et al. 2011) (see Table 1 for further details) and comprised material from 17 origins in Quebec and Ontario (Supplemental Table S1). We sampled 4-6 trees per site for each of the 33 full-sib families corresponding to 369 genotypes in total. The clonal tests comprised lines that were developed in two independent programs by the MFFP and JDI using somatic embryogenesis and deployed in two independent series. The Quebec clonal trial was established in 2010 on two sites: (1) Saint-Modeste in the balsam firyellow birch ecological domain, and (2) Grandes-Piles in the sugar maple-yellow birch ecological domain (Saucier et al. 2011). We sampled a total of 215 trees from 21 clonal lines (distinct genotypes) representing 16 provenances from Quebec and Ontario (8-10 ramets per clonal line) (Supplemental Table S2). The clonal trials in New Brunswick represented 42 provenances from New Brunswick and Maine and were established in 2000 at three different sites:

(1) Black Brook, (2) Deersdale, and (3) Parkindale (see Table 1 for further details). We sampled a total of 290 trees corresponding to 50 different clonal lines (3-6 trees per clonal lineage).

The following tree growth data were available: in the Quebec progeny trials: total tree height at year 9 ranging from 1.2 to $5.1 \mathrm{~m}$; in the Quebec clonal trials: total tree height at 6 years ranging from 0.48 to $2.7 \mathrm{~m}$ and height growth increment also at year 3 and year 6 based on initial and final heights ranged from 0.026 to $0.633 \mathrm{~m}$. Many of the trees were too small for stem diameter to be a useful assessment of growth.

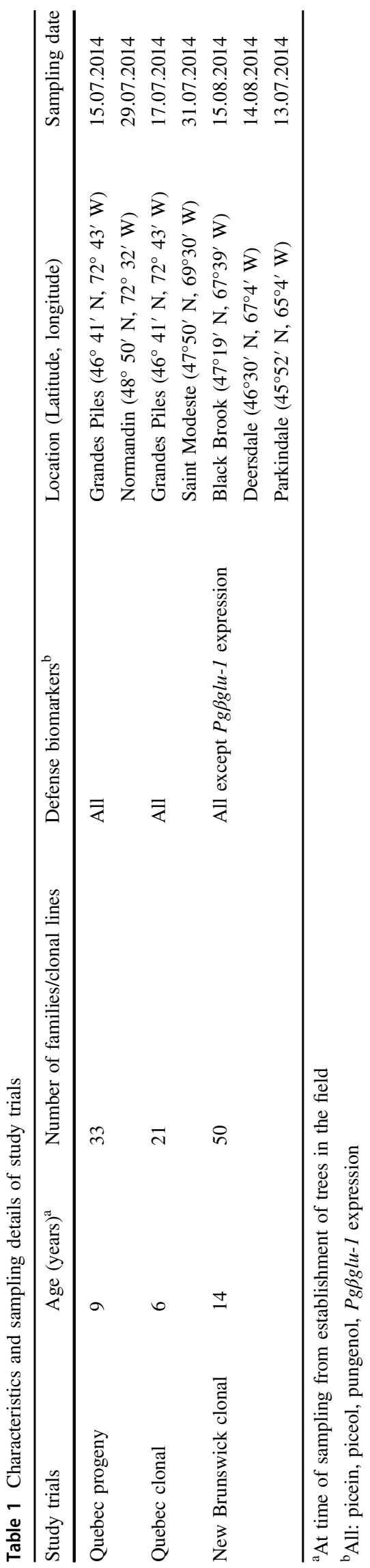




\section{Tissue sampling and preparation}

Current-year foliage was used for all of the analyses as it is the main target tissue of herbivory and was used in recent investigations of this resistance mechanism (Parent et al. 2017). Tissues were sampled between the 15 th of July and the 15th August of 2014, when the acetophenone levels have reached a high and stable level in contrast to earlier phenological stages when the levels are increasing rapidly in the more resistant trees (Parent et al. 2017). The foliage was sampled from the north side in the middle third of the tree crown as in previous studies on resistance to SBW herbivory (Wagner et al. 1990; Delvas et al. 2011; Mageroy et al. 2014). The sampling involved cutting off a piece of shoot representing the current-year growth at the tip of branches and immediately freezing and maintaining them in liquid nitrogen or at $-80^{\circ} \mathrm{C}$ until further processing. Frozen foliage was removed from the shoot by swirling the shoot in liquid nitrogen and then was ground with a MixerMill 300 (Retsch, Haan, Germany) by using steel grinding balls previously frozen in liquid nitrogen. The tissue powder was kept at $-80^{\circ} \mathrm{C}$ until RNA and phenolic compounds extractions were made.

\section{RNA extraction}

Total RNA was isolated from frozen tissues following the method of Chang et al. (1993), with modifications (Pavy et al. 2008). Total RNA concentrations were determined with a spectrophotometer Nanodrop 1000 (Thermo Scientific, Wilmington, DE, USA) and RNA quality was assessed using the Agilent 2100 Bioanalyzer with RNA 6000 Nano LabChips (Agilent Technologies Inc, Santa Clara, CA, USA).

\section{RT quantitative PCR}

We used $500 \mathrm{ng}$ of total RNA for complementary DNA synthesis with the Superscript First-Strand cDNA system (Invitrogen) as described in Mageroy et al. (2014). The PCR mixtures were prepared with the quantiFast SYBR Green PCR kit (Qiagen) as presented in Parent et al. (2017). Pgßglu-1 gene (GQ03511_F06-R1) specific 5' and $3^{\prime}$ primers were used to amplify a sequence fragment and quantify the number of transcripts (See Mageroy et al. (2014) for details). Amplifications were performed in a LightCycler 480 (Roche Diagnostics, Rotkreuz, Switzerland) as described in Boyle et al. (2009). We calculated the number of transcript molecules with the LRE method (Rutledge and Stewart 2008) adapted by Boyle et al. (2009), normalized to a ratio calculated by the geometric mean of three reference genes: ribosomal protein L3A (BT115036), elongation factor 1a (EF1- $\alpha)(B T 102965)$, and cell division cycle 2 (CDC2) (BT106071) (Beaulieu et al. 2013).

\section{Extraction and quantification of phenolic compounds}

Acetophenones were extracted as described in Mageroy et al. (2014). Picein, piceol, and pungenol were identified and quantified by HPLC-MS (Agilent 1200 series and Agilent 6210 TOF) as described in Parent et al. (2017). The resulting chromatograms were processed with the Agilent MassHunter Workstation Data Acquisition software version B.01.04 (Agilent Technologies) and quantification was performed using calibration curves.

\section{Data analysis}

\section{Heritability estimates}

Narrow-sense heritability $\left(h^{2}\right)$ was estimated based on progeny trials and broad-sense heritability $\left(H^{2}\right)$ was estimated based on clonal trials. The variance components were calculated with mixed model equations and restricted maximum likelihood in the MIXED procedure in SAS 9.4. The site effect was considered fixed as suggested by Holland (2006), and the family (progeny trials) or the clonal line (clonal trials) as random effects. For both types of trials, the site-by-family interaction effect was removed from the analysis, because their contribution to the total variance was negligible or zero. Hence including the interaction term did not improve the model fit and increased the AIC (Akaike information criterion). The block within site effect was initially considered in the clonal trials but was not retained for the same reasons. Therefore, the model was reduced to:

$$
Y_{i j k}=\mu+S_{i}+F_{j}+\varepsilon_{i j k},
$$

where $Y_{i j k}$ is the observation of the $k$ th tree in the $i$ th site of the $j$ th family or clone, $\mu$ is the overall mean of each character, $S_{i}$ is the fixed effect of the $i$ th site, $F_{j}$ is the random effect of $j$ th family (progeny trials) or the $j$ th clone (clonal trials), and $\varepsilon_{i j k}$ is the random error. Normality of studentized residuals was inspected visually and using the Shapiro-Wilk test (UNIVARIATE procedure in SAS 9.4) considering normality of errors at $P>0.05$.

Data transformation was used in several cases because normality of residuals was not respected. A logarithmic transformation was applied to all of the traits in the progeny trials. For the Quebec and New Brunswick clonal trials, square root transformation was performed for the acetophenones. 
Narrow-sense heritability was estimated in the progeny trials as:

$h^{2}=\frac{2 * \sigma_{\mathrm{Fam}}^{2}}{\sigma_{\mathrm{Fam}}^{2}+\sigma_{\varepsilon}^{2}}$,

where $\sigma_{\text {Fam }}^{2}$ is the estimated family variance and $\sigma_{\varepsilon}^{2}$ is the error variance.

Broad-sense heritability was estimated in the clonal trials using the inter-clonal variance:

$$
H^{2}=\frac{\sigma_{\text {Clone }}^{2}}{\sigma_{\text {Clone }}^{2}+\sigma_{\varepsilon}^{2}},
$$

where $\sigma^{2}$ Clone is the clonal variance and $\sigma^{2} \varepsilon$ is the error variance. Errors associated to heritability estimates were calculated by the Delta method (Lynch and Walsh 1998).

\section{Genetic and phenotypic correlations between defense traits}

In order to investigate how defense traits are related among each other, genetic and phenotypic correlations between trait pairs were calculated using a multivariate approach adapted from Holland (2006) as:

$r_{(x, y)}=\frac{\operatorname{cov}_{(x, y)}}{\sqrt{\sigma_{x}^{2} \times \sigma_{y}^{2}}}$,

where $\sigma_{x}^{2}$ and $\sigma_{y}^{2}$ are variance components for two traits, and $\operatorname{cov}_{(x, y)}$ is the covariance between a pair of traits. For genetic correlations, genotypic variance-covariance estimates based on the family or clone effect were used; whereas phenotypic correlations used phenotype variance -covariance, that is the sum of genetic and error components.

\section{Trade-offs between growth and resistance against the SBW}

Evaluation of trade-offs used height growth data, which were available for the Quebec progeny and clonal trials. In a genetic and evolutionary perspective, trade-offs have been defined as a negative, genetically based, relationship between traits (Reznick 1985). Therefore, trade-offs between tree growth and resistance were evaluated based on two criteria as suggested by Leinekugel le Cocq et al. (2005), Sampedro et al. (2011), and Moreira et al. (2013): Pearson correlation tests and genetic correlations. We also estimated the correlated response to selection between the defense biomarkers and growth based on the indirect selection efficiency (ISE), which describes to what extent the mean of trait $x$ can be shifted (or how much of its genetic gain can be realized) through selection on trait $y$
(White et al. 2007):

$I S E_{x, y}=\frac{i_{x} \times h_{x}}{i_{y} \times h_{y}} \times r_{\mathrm{G}}$,

where $h_{x}$ and $h_{y}$ are the square root of trait heritability estimates for trait $x$ and $y$, respectively and $r_{\mathrm{G}}$ is the genetic correlation between both traits. The selection intensity was considered to be equal for both traits $i_{x}=i_{y}$; therefore, we canceled them to simplify the equation. The further away from zero the ISE coefficients are, the stronger the correlated response will be whether it is positive or negative. The defense biomarkers were considered the selected traits $(y)$ seeing as the SBW exerts a direct pressure on white spruce trees according to the accumulation of resistance metabolites in the foliage (Parent et al. 2017), while tree growth is the unselected trait $(x)$.

Initial and final heights were measured in autumn 2011 and 2014, respectively. Height increment was calculated with the formula:

Height increment $=\frac{\text { Total final height }- \text { Total initial height }}{\text { Time between final and initial height }(\text { years })}$

\section{Results}

We investigated the genetic control of constitutive levels of four SBW defense biomarkers in $P$. glauca: the acetophenone aglycons piceol and pungenol, the acetophenone glucoside picein, and the expression of the gene Pgßglu-1. Phenotypic determinations were carried out in 33 full-sib families growing in a progeny trial replicated on two test sites in Quebec and 71 clonal lines growing in five different test sites in Quebec and New Brunswick.

\section{Large phenotypic variation in defense biomarkers}

The phenotypic variation was broad for all of the defense biomarkers both in the progeny and clonal trials. The acetophenones and the $P g \beta g l u-1$ gene transcripts ranged from not detected (reported as 0) to high levels. Picein was the most abundant secondary metabolite with averages exceeding $10 \%$ of the foliar dry weight (Table 2). Piceol and pungenol had lower levels, just below 4 and $2 \%$ of the foliar dry weight on average, respectively. Gene expression was 7.0-10.2 $\log _{2} \mathrm{ng}^{-1}$ RNA, which represents $128-1206$ transcript molecules per ng of RNA.

Overall, each of the defense biomarkers showed consistent frequency distribution trends across the progeny and clonal trials even though the age, site conditions, and genotypes evaluated were different in each set of trials (Fig. 1). 
Table 2 Phenotypic variation of picein and resistance biomarkers. Minimum and maximum values, mean \pm standard error are presented for the three different series of trials

\begin{tabular}{|c|c|c|c|c|}
\hline Study trials & $\begin{array}{l}\text { Picein }\left(\mathrm{mg} \mathrm{g}^{-1}\right. \\
\text { dry tissue) }\end{array}$ & $\begin{array}{l}\text { Piceol }\left(\mathrm{mg} \mathrm{g}^{-1}\right. \\
\text { dry tissue) }\end{array}$ & $\begin{array}{l}\text { Pungenol ( } \mathrm{mg} \mathrm{g}^{-1} \\
\text { dry tissue) }\end{array}$ & $\begin{array}{l}\text { Pg } \beta g l u-1 \text { expression } \\
\left(\log _{2} \mathrm{ng}^{-1} \text { RNA) }\right.\end{array}$ \\
\hline \multirow[t]{2}{*}{ Quebec progeny } & $0.0-574.0$ & $0.0-84.5$ & $0.0-132.6$ & $0.0-17.8$ \\
\hline & $116.3 \pm 4.16$ & $9.6 \pm 0.71$ & $17.4 \pm 1.17$ & $10.2 \pm 0.23$ \\
\hline \multirow[t]{2}{*}{ Quebec clonal } & $0.0-279.0$ & $0.0-65.6$ & $0.0-44.0$ & $0.0-13.3$ \\
\hline & $115.4 \pm 3.92$ & $15.4 \pm 1.23$ & $6.2 \pm 0.56$ & $7.0 \pm 0.26$ \\
\hline \multirow{2}{*}{$\begin{array}{l}\text { New Brunswick } \\
\text { clonal }\end{array}$} & $0.0-295.8$ & $0.0-218.6$ & $0.0-75.0$ & ND \\
\hline & $95.4 \pm 3.78$ & $35.2 \pm 2.20$ & $12.7 \pm 0.81$ & \\
\hline
\end{tabular}

The distributions were slightly positively skewed for picein, piceol, and pungenol, as they accumulated to low levels in a large proportion of the individuals and had a wide range of higher concentrations in the remainder of the population. In contrast, the Pgßglu-1 gene expression had a negatively skewed distribution. The mixed model analyses indicated highly significant effects of the site (fixed effect) and the family or clonal line (random effects) for all of the defense biomarkers with the site effect in the progeny trials for picein as the only exception (Table 3 ).

\section{Phenotypic variation in defense traits is under strong genetic control}

Phenotypic data from the full-sib progeny trials and clonal trials were analyzed to estimate narrow-sense and broadsense heritability, respectively. The narrow-sense heritability estimates were moderate to high, ranging from 0.50 \pm 0.07 to $0.60 \pm 0.06$ for acetophenone compounds and $0.58 \pm 0.07$ for the PgBglu-1 gene expression (Table 4). This indicates that the four traits are under strong additive genetic control.

The broad-sense heritability was evaluated separately for two independent clonal trials (Quebec and New Brunswick). High heritability estimates were obtained for each of the resistance traits in the Quebec clonal trials. The broad-sense heritabilities of the acetophenone compounds were 10-20\% higher than the narrow-sense heritabilities estimates obtained from the progeny trials; while the heritability estimate for gene expression was marginally lower than the narrow-sense heritability $(0.55 \pm 0.08)$ (Table $5)$. The observation of higher levels of broad-sense heritability may indicate that the genetic control of the acetophenones combine both additive and non-additive control although the estimates were derived from different study populations and growth sites (Table 3). Broad-sense heritability estimates from the New Brunswick clonal trials were notably lower ranging from $0.23 \pm 0.06$ to $0.37 \pm 0.06$ (Table 5).

\section{The SBW resistance biomarkers are highly correlated genetically and phenotypically}

Analyses of the progeny trial data indicated strong positive genetic $\left(r_{\mathrm{G}}\right)$ and phenotypic $\left(r_{\mathrm{P}}\right)$ correlations between the acetophenones piceol and pungenol $\left(r_{\mathrm{G}}=0.88 ; r_{\mathrm{P}}=0.80\right)$ (Table 4). Similarly, these same acetophenone compounds had strong positive genetic and phenotypic correlations with $P g \beta g l u-1$ gene expression $\left(r_{\mathrm{G}}=0.91 ; r_{\mathrm{P}}=\right.$ from 0.70 to 0.75). In contrast, the correlations between acetophenone glucoside picein and the three resistance biomarkers were low or negative $\left(r_{\mathrm{G}}=-0.34\right.$ to $0.03 ; r_{\mathrm{P}}=-0.27$ to 0.01$)$ confirming the findings of Mageroy et al. (2014) that high levels of picein are not related to the accumulation of resistance metabolites. The same trends were observed in the two clonal trial series and in some cases larger negative correlations were found between picein and the resistance biomarkers $\left(r_{\mathrm{G}}=\right.$ from -0.80 to $0.16 ; r_{\mathrm{P}}=-0.50$ to 0.11 ) (Table 5).

\section{A trade-off is detected for picein but not between resistance biomarkers and growth}

Potential trade-offs were evaluated following two separate approaches. Firstly, Pearson correlations were calculated between growth (total height and height increment) and acetophenones (picein, piceol, pungenol) and Pgקglu-1 gene expression in the progeny and clonal trials located in Quebec. The acetophenone glucoside picein was negatively correlated with both total tree height and height increment (from -0.02 to -0.27 ) and in contrast, we found positive and significant correlations $(r=0.14$ to 0.28$)$ between height and the SBW resistance biomarkers (Table 6).

Secondly, genetic correlations between picein and height traits were mainly negative albeit low $\left(r_{\mathrm{G}}=\right.$ from -0.30 to 0.01 ), which is consistent with the result obtained from the phenotypic correlations. Positive genetic correlations of 0.16-0.38 were observed between the SBW resistance biomarkers (piceol, pungenol, and $P g \beta g l u-1$ expression) 


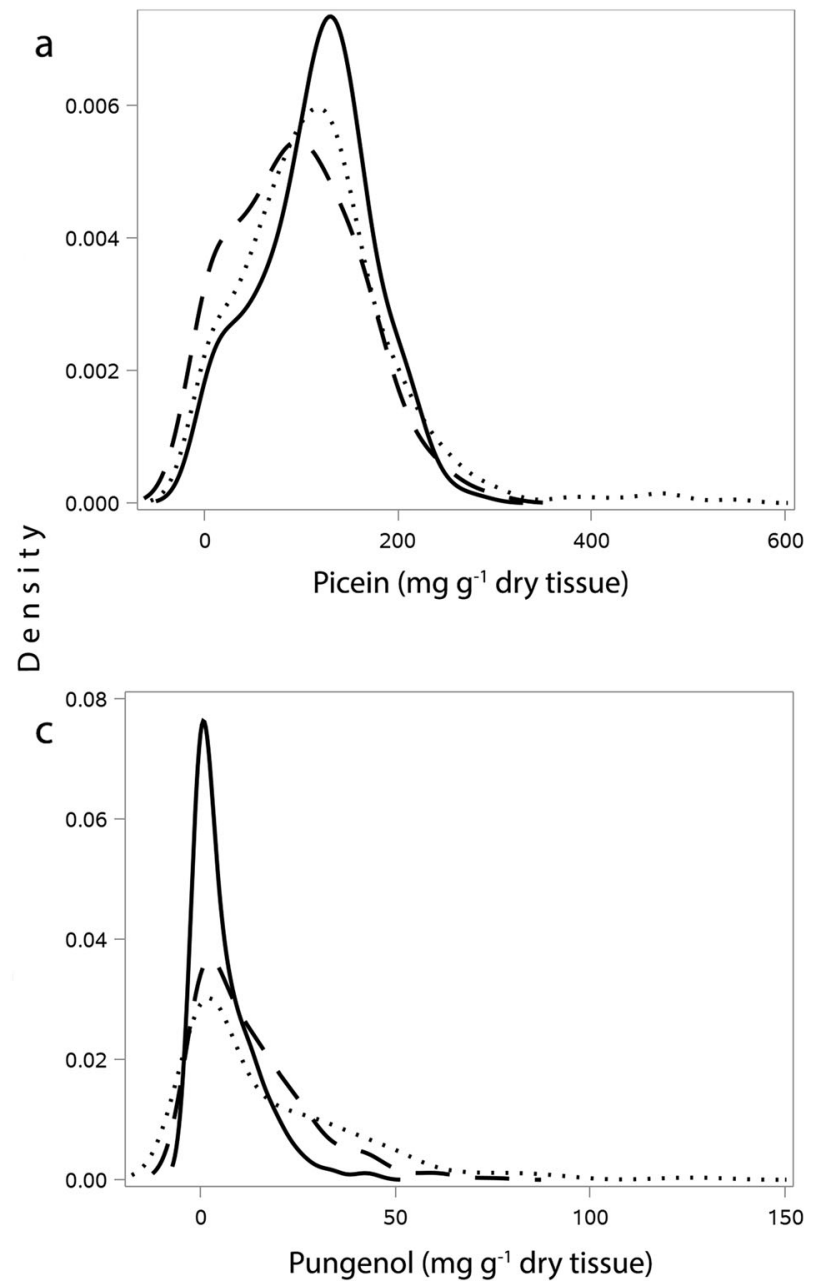

Fig. 1 Density plots for a picein, b piceol, c pungenol and d Pgbglu-1 gene expression of full-sib progeny and clonal trials. In the graph, solid lines, dot lines, and dash lines represent the Quebec progeny trials, Quebec clonal trials, and New Brunswick clonal trials,

and height traits; the highest correlations were obtained for height increment $\left(r_{\mathrm{G}}=0.30\right.$ to 0.56$)$ (Table 6$)$. Together, these observations indicate that there is no trade-off between the SBW resistance mechanism studied here and tree growth in young white spruce trees.

To further investigate the trade-offs, we also calculated the ISE (Table 6). The coefficients of the ISE for the resistance biomarkers ranged from 0.18 to 1.26 while those between picein and the tree growth traits from the clonal trials were mainly negative ranging from -0.28 to -0.76 .

\section{Discussion}

We quantified the accumulation of picein, piceol, pungenol, and transcripts of the $P g \beta g l u-1$ gene in the foliage of $874 P$. glauca trees in seven different sites to evaluate their heritability. All of the trees used in this study are from
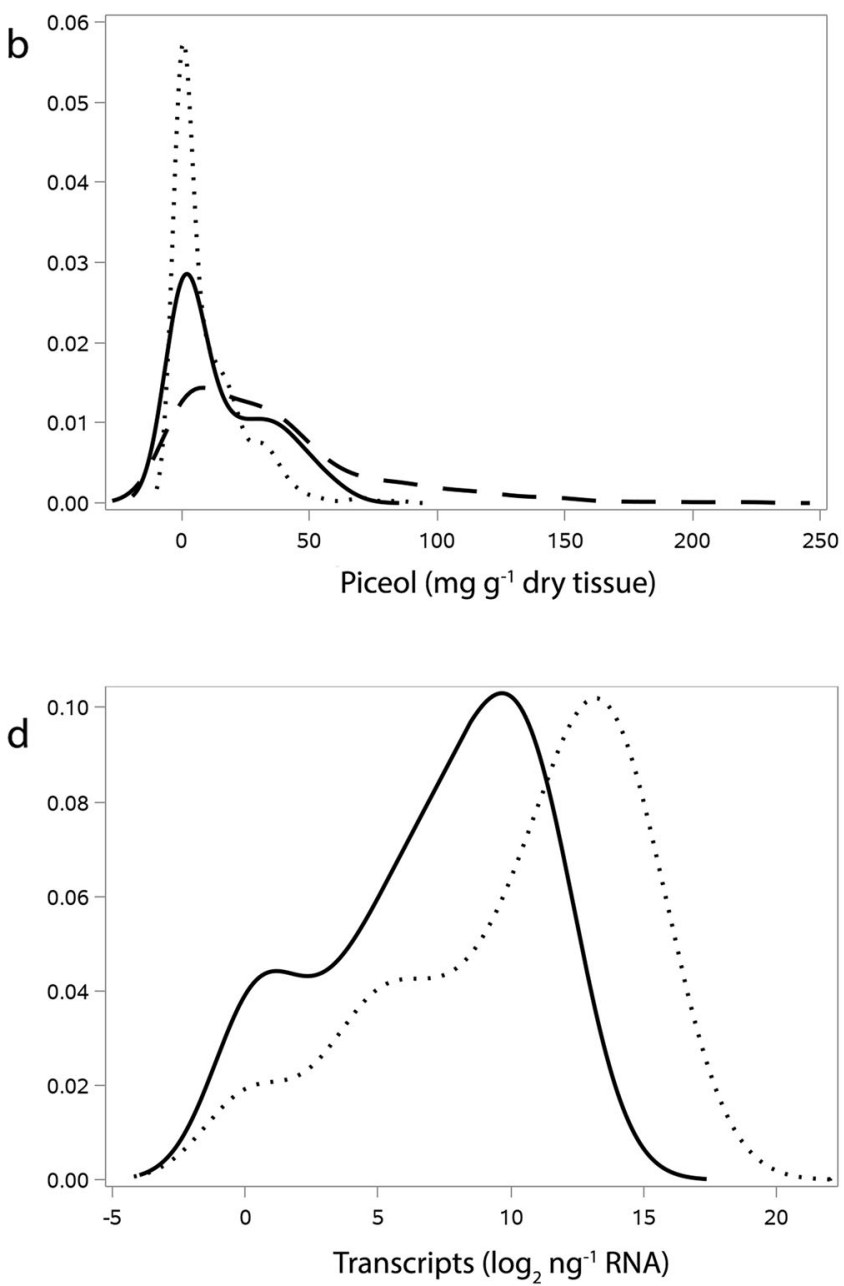

respectively. Kernel density estimates were characterized with the SGPLOT procedure in SAS version 9.4. All trials are included in the density plots for phenolic compounds and only the Quebec trials are considered for transcripts of Pgbglu-1 gene (see Methods)

experimental plantations that have been healthy and free from any noticeable insect attack or disease. Therefore, we may assume that we have measured constitutive levels of defense. Moreover, the constitutive nature of the resistance mechanism linked to the acetophenones piceol and pungenol was previously shown by Mageroy et al. (2014) and Parent et al. (2017). We discuss the contribution of this work for understanding the genetic control of insect resistance and the potential costs of defense on tree growth in an evolutionary context.

\section{Genetic control of SBW defense biomarkers}

We observed broad phenotypic variation in all four of the defense biomarkers, which is a prior condition for evolution (Lande and Arnold 1983). We analyzed full-sib families tested in two different ecological regions and obtained heritability estimates ranging from moderate to high; no 


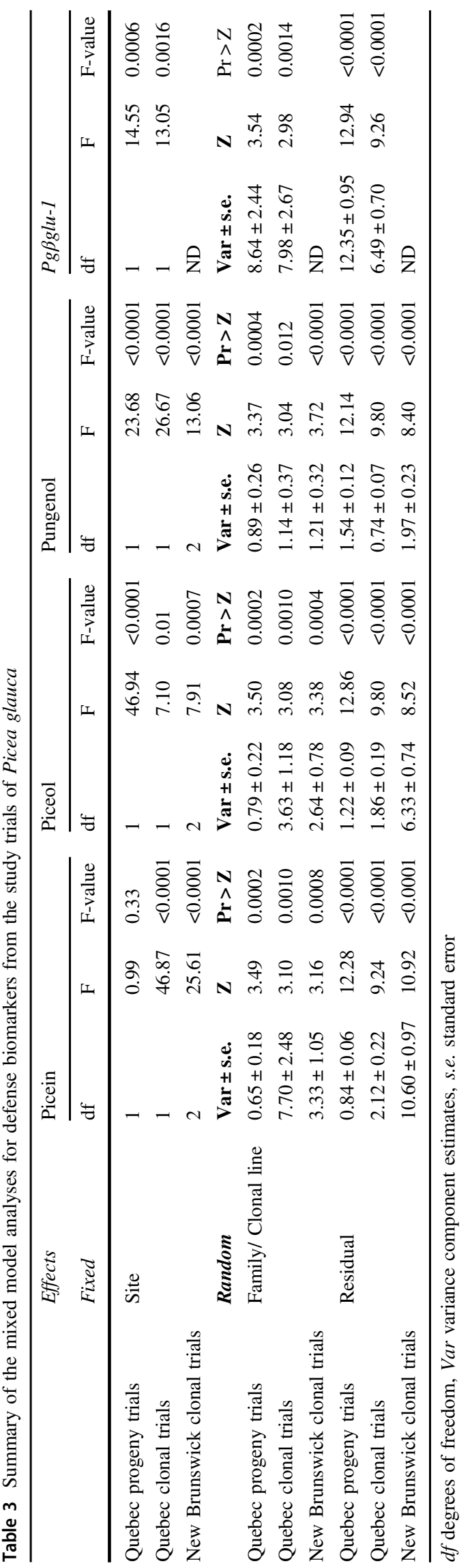

significant interactions were observed between genotype and environment. Our results in white spruce indicate the importance of heritable additive variation, a determinant of the short-term evolutionary potential (Hansen et al. 2011). Such findings are consistent with recent work in this system, indicating that these phenotypic traits had high levels of constitutive variability (Mageroy et al. 2014) and similar estimates for genetic control (Parent et al. 2017). The former study reported higher narrow-sense heritability estimates $\left(h^{2}\right)$ for piceol and pungenol and lower $h^{2}$ for picein. However, the heritability estimates in Parent et al. (2017) may be biased because they were based on a set of largely unrelated genotypes (Squillace 1974) from a single site.

Our findings differ from studies evaluating the resistance of $P$. glauca against different insect species. For example, resistance against the spruce bud moth (Zeiraphera canadensis) showed low heritability $\left(h^{2}=0.26\right)$ and large genotype and environment interactions (Quiring et al. 1991). Elevated heritability of resistance against the stem piercing white pine weevil (Pissodes strobi) was estimated, $h^{2}=$ $0.70( \pm 0.12)$ (King et al. 1997); however, only one site was evaluated such that environmental effects were not quantified and heritability estimates may be inflated.

On the other hand, similar findings to ours were obtained for insect resistance in other Picea species. In interior spruce $(P$. glauca $\times P$. engelmannii), a high level of heritable resistance $\left(h^{2}=0.77 \pm 0.11\right)$ was observed against the white pine weevil (Pissodes strobi) when tested in three progeny trials (Kiss and Yanchuck 1991). In the same system, Alfaro et al. (2004) screened the F1 of controlled crosses between Resistant (R) and Susceptible (S) parents and observed that progeny of $\mathrm{R} \times \mathrm{S}$ crosses had intermediate resistance compared to $\mathrm{R} \times \mathrm{R}$ and $\mathrm{S} \times \mathrm{S}$ crosses, as anticipated for an additive genetic model.

Research into other genera of forest trees also reported high levels of heritability for some insect resistance traits. For example, two defensive traits including non-volatile resin in the stem and total phenolics in the foliage were studied in Pinus radiata and gave contrasting results (Moreira et al. 2013). The heritability estimates for the nonvolatile resin were much more elevated $\left(h^{2}=0.91 \pm 0.20\right)$ than those for foliar phenolics $\left(h^{2}=0.18 \pm 0.11\right)$. The study obtained high errors associated with the heritability estimates, unlike our work where errors ranged from 0.04 to 0.08 (see Tables 4 and 5).

Very few studies on insect resistance in forest trees report on both narrow- and broad-sense heritability. We obtained slightly higher broad-sense heritability estimates for acetophenones (picein, $H^{2}=0.77 \pm 0.05$; piceol, $H^{2}=0.66 \pm$ 0.07; pungenol, $H^{2}=0.60 \pm 0.08$ ) and Pgקglu-1 gene expression $\left(H^{2}=0.55 \pm 0.08\right)$ than the narrow-sense estimates $\left(h^{2}\right)$ for the clonal trials in Quebec. However, the coefficients of $H^{2}$ for the New Brunswick clonal trials were 
Table 4 Narrow-sense heritability estimates $\left(h^{2} \pm\right.$ standard error, s.e.), genetic correlations $\left(r_{\mathrm{G}} \pm\right.$ s.e. $)$, and phenotypic correlations $\left(r_{\mathrm{P}} \pm\right.$ s.e. $)$ for picein and resistance biomarkers in Quebec progeny trials of Picea glauca

\begin{tabular}{lllll}
\hline & Picein & Piceol & Pungenol & Pg/glu-1 expression \\
\hline Picein & $\mathbf{0 . 6 0} \pm \mathbf{0 . 0 6}$ & $-0.34 \pm 0.17$ & $0.03 \pm 0.20$ & $-0.15 \pm 0.19$ \\
Piceol & $-0.27 \pm 0.08$ & $\mathbf{0 . 5 5} \pm \mathbf{0 . 0 7}$ & $0.88 \pm 0.04$ & $0.91 \pm 0.04$ \\
Pungenol & $0.01 \pm 0.08$ & $0.80 \pm 0.02$ & $\mathbf{0 . 5 0} \pm \mathbf{0 . 0 7}$ & $0.91 \pm 0.04$ \\
Pg gglu-1 expression & $-0.14 \pm 0.08$ & $0.70 \pm 0.03$ & $0.75 \pm 0.03$ & $\mathbf{0 . 5 8} \pm \mathbf{0 . 0 7}$ \\
\hline
\end{tabular}

The table shows genetic correlations (above diagonal), phenotypic correlations (below the diagonal), and heritability estimates (on the main diagonal, in boldface).

lower for the acetophenones (pungenol, $H^{2}=0.41 \pm 0.06$; piceol, $H^{2}=0.39 \pm 0.06$; picein, $\left.H^{2}=0.21 \pm 0.06\right)$. These differences likely reflect the smaller sample size used in New Brunswick (one sample tree per site for some clones).

In black spruce (Picea mariana), an estimate of $\mathrm{H}^{2}=$ 0.40 was obtained for resistance against the yellowhead spruce sawfly (Pikonema alaskensis) based on an assessment of 35 clonal lineages in a single plantation site (Leinekugel le Cocq et al. 2005). High broad-sense heritability estimates were obtained for phenolic glucosides $\left(H^{2}=\right.$ $0.718)$ and condensed tannins $\left(H^{2}=0.584\right)$ in aspen (Populus tremuloides) grown in the greenhouse under four nutrient-defoliation treatment combinations (Stevens et al. 2007). Interestingly, we obtained a very similar $H^{2}$ estimate for picein (also a phenolic glucoside) in the Quebec trials than that reported in aspen (P. tremuloides) by Stevens et al. (2007). A recent study assessed the resistance against white pine weevil (Pissodes strobi) in Norway spruce (Picea abies) on a very large set of full-sib families in three sites and the results indicated that non-additive effects may have a smaller influence on resistance than additive effects (Mottet et al. 2015), like our results suggest.

We found strong positive genetic correlations between the acetophenones piceol and pungenol $\left(r_{\mathrm{G}}\right.$ from 0.70 to 0.88 ) and with $P g \beta g l u-1$ gene expression $\left(r_{\mathrm{G}}\right.$ from 0.87 to $0.91)$. These genetic correlations may indicate that the same sets of genes are responsible for their control and this is expected because the $P g \beta g l u-1$ gene product was proposed to catalyze the release of both piceol and pungenol (Mageroy et al. 2014); however, these genetic components remain unknown.

In contrast, we found mainly weaker and negative genetic correlations between picein and the aglycon acetophenones ( $r_{\mathrm{G}}$ ranging from -0.08 to -0.83 ) and $\mathrm{Pg} \beta g l u-1$ gene expression $\left(r_{\mathrm{G}}\right.$ from -0.23 to -0.24$)$. These observations may appear unexpected because picein is the precursor for the production of piceol (Mageroy et al. 2014) but are consistent with their very different levels of accumulation, with picein reaching much higher concentrations in some trees. These results indicate that picein is under the control of different genetic factors, which stands to reason because it appears to be non-limiting for SBW resistance
(Mageroy et al. 2014; Parent et al. 2017). Similar trends were observed for the phenotypic correlations.

The prediction of the response to selection on the short and long term is beyond the scope of this study; however, over a single generation this could be evaluated with the breeder's equation, which requires the heritability estimates and the selection differential (Falconer and MacKay 1996). For the long-term response, studying the genetic basis of variability in resistance traits would improve our understanding of fitness and demographic success (Pearse et al. 2015) and may shed light on the potential effects of plant resistance on other trophic levels (Whitham et al. 2003). For the long-term response we cannot extrapolate from the breeder's equation because the effects of selection over long intervals are unpredictable (Falconer and MacKay 1996). However, the possible outcomes could be modeled by using genetic data of the traits including the level of genetic variation, the number of underlying loci, the proportion of phenotypic variation caused by each locus, and the mutation rate in these loci in a specific population (Hamilton 2009).

\section{Trait correlations and trade-offs between resistance against the SBW and growth}

Our findings from the analysis of phenotypic and genetic correlation did not provide any evidence of trade-offs between growth and SBW resistance biomarkers but indicated that trade-offs may be expected between growth and picein. We discuss our findings in view of trade-off theories in plants and recent work in conifer trees.

Positive phenotypic correlations (Pearson $r=0.14$ to $0.30)$ and genetic correlations $\left(r_{\mathrm{G}}=0.12\right.$ to 0.56$)$ were obtained between the three SBW resistance biomarkers and tree height (Table 6). This indicated that the accumulation of aglycon acetophenones is not associated with decreased growth in $P$. glauca. The positive, albeit low, correlations may indicate that more vigorous trees have more active defenses, although further testing is required. The trees analyzed for trade-offs in the present report were still young (6-9 years old) and varied considerably in size $(0.48-5.1$ $\mathrm{m})$, suggesting that resistance levels may be positively associated to size and age, which would stand to reason in 
Table 5 Broad-sense heritability estimates $\left(H^{2} \pm\right.$ standard error, s.e.), genetic correlations $\left(r_{\mathrm{G}} \pm\right.$ s.e. $)$, and phenotypic correlations $\left(r_{\mathrm{P}} \pm\right.$ s.e. $)$ for picein and resistance biomarkers in Quebec and New Brunswick clonal trials of Picea glauca

\begin{tabular}{|c|c|c|c|c|}
\hline Clonal trials & Picein & Piceol & Pungenol & $P g \beta g l u-1$ expression \\
\hline \multicolumn{5}{|l|}{ Quebec } \\
\hline Picein & $0.77 \pm 0.05$ & $0.16 \pm 0.22$ & $-0.26 \pm 0.21$ & $-0.17 \pm 0.22$ \\
\hline Piceol & $0.11 \pm 0.16$ & $0.66 \pm 0.07$ & $0.79 \pm 0.08$ & $0.87 \pm 0.05$ \\
\hline Pungenol & $-0.26 \pm 0.14$ & $0.78 \pm 0.05$ & $0.60 \pm 0.08$ & $0.88 \pm 0.05$ \\
\hline$P g \beta g l u-1$ expression & $-0.15 \pm 0.14$ & $0.74 \pm 0.05$ & $0.72 \pm 0.05$ & $0.55 \pm 0.08$ \\
\hline \multicolumn{5}{|l|}{ New Brunswick } \\
\hline Picein & $0.23 \pm 0.06$ & $-0.46 \pm 0.19$ & $-0.80 \pm 0.11$ & ND \\
\hline Piceol & $-0.07 \pm 0.06$ & $0.29 \pm 0.07$ & $0.75 \pm 0.09$ & ND \\
\hline Pungenol & $-0.50 \pm 0.05$ & $0.61 \pm 0.04$ & $0.37 \pm 0.06$ & ND \\
\hline
\end{tabular}

The table shows genetic correlations (above diagonal), phenotypic correlations (below the diagonal), and heritability estimates (on the main diagonal, in boldface).

Table 6 Trade-offs between growth traits and picein and defense biomarkers for Quebec progeny and clonal trials of Picea glauca

\begin{tabular}{lllll}
\hline Growth trait Trial & Picein & Piceol & Pungenol & $\begin{array}{l}\text { Pgßglu-1 } \\
\text { expression }\end{array}$ \\
\hline
\end{tabular}

\begin{tabular}{llllll}
\hline \multicolumn{5}{c}{$\begin{array}{l}\text { Phenotypic correlations (Pearson correlation } \\
\text { coefficients) }\end{array}$} \\
Total height & Progeny & -0.02 & $0.16^{* *}$ & $0.24^{* *}$ & $0.16^{* * *}$ \\
& Clonal & $-0.24^{* *}$ & $0.14^{*}$ & $0.28^{* *}$ & $0.15^{* *}$ \\
Increment & Clonal & $-0.27^{* *}$ & $0.15^{*}$ & $0.30^{* *}$ & $0.18^{* * *}$ \\
& Genetic correlations \\
Total height & Progeny & $0.01 \pm$ & $0.16 \pm$ & $0.38 \pm 0.04$ & $0.27 \pm 0.19$ \\
& & 0.21 & 0.01 \\
Increment & Clonal & $-0.13 \pm$ & $0.16 \pm$ & $0.37 \pm 0.24$ & $0.12 \pm 0.27$ \\
& & 0.26 & 0.26 & & \\
Total height & $-0.30 \pm$ & $0.30 \pm$ & $0.56 \pm 0.22$ & $0.34 \pm 0.27$ \\
& Indirect selection efficiency, ISE & \\
Increment & Progeny & 0.01 & 0.18 & 0.42 & 0.32 \\
& Clonal & -0.28 & 0.32 & 0.71 & 0.22 \\
\hline & Clonal & -0.76 & 0.71 & 1.26 & 0.73 \\
\hline
\end{tabular}

Phenotypic correlations are significant at the $* p<0.05$ and $* * p<0.01$ levels. $r_{\mathrm{G}} \pm$ standard error are presented for genetic correlations.

light of the preference of SBW for mature trees (MacLean 1984). This would not represent an isolated case; for example, ontogenetic changes in defense traits have been observed in trees including Betula, Salix, and Eucalyptus, among others (Boege and Marquis 2005).

The constitutive levels of foliar piceol and pungenol reported here and in previous work (Delvas et al. 2011; Mageroy et al. 2014; Parent et al. 2017) fit with a premise of the ODT theory indicating that plant structures more prone to attack are those that are better defended, but not with the assumption of cost. In a review of 159 North American angiosperms, Loehle (1987) found strong support for tradeoffs between growth and defense in woody plants but due to a lack of data in the analysis, no support was found in gymnosperms. The work of Fine et al. (2006) also strongly supported the trade-offs hypothesis, according to their examination of five angiosperm plant families in the Peruvian Amazon, although the issue has been a matter of long-standing debate in the scientific literature.

Recent studies in conifers have also reported a lack of evidence for trade-offs between constitutive defense levels and growth. In balsam fir (Abies balsamea), a member of the Pinaceae along with spruce, Deslauriers et al. (2015) assessed the effect of defoliation on carbon allocation and found no evidence of trade-off with growth. In the same way, no evidence for trade-offs was found between growth and defense in Pinus pinaster (Sampedro et al. 2011) and Pinus radiata (Moreira et al. 2013).

In our study, negative phenotypic (Pearson $r=-0.24$ to $-0.27)$ and genetic correlations $\left(r_{\mathrm{G}}=-0.30\right.$ to -0.13$)$ were found between the acetophenone glucoside picein and tree height traits in the clonal trials. These results indicate that picein may have a cost on growth as predicted for both the ODT theory and the GDBH hypothesis (Rhoades 1979; Herms and Mattson 1992). We acknowledge that this interpretation warrants further testing because our results were not consistent between the populations tested in the clonal trials compared to the progeny trials, which did not give negative correlations, and because the role of picein has not been clearly established in resistance against the SBW (Mageroy et al. 2014; Parent et al. 2017). In addition, research has shown that the sense of the correlations can be inversed when environmental conditions change (Sgrò and Hoffmann 2004). Our results are based on evaluations in two contrasting environments for each population; as such, they may well represent the effects of different conditions and did not reveal any genotype $\times$ environment interactions, but future work could dissect the effects by testing wider gradients of environmental effects. 
The role of picein has not been established in resistance against the SBW in white spruce (Mageroy et al. 2014; Parent et al. 2017), although it has been suggested to confer diverse types of defense in other conifer species. For example, it accumulates in the foliage of some Norway spruce when infected by the fungus Sirococcus conigenus (Bahnweg et al. 2000), indicating a potential role in inducible defense (Osswald and Benz 1987). Picein is the precursor of piceol, which is phytotoxic in Norway spruce (Picea abies) at $500 \mathrm{mg} \mathrm{L}^{-1}$ as indicated by yellowing and browning of foliage and inhibition of bud break (Hoque 1985). We found that the levels of picein (10\% of dry weight on average) were much higher than those of piceol and pungenol (0.96-3.52\% of foliar dry weight on average) and that correlations between the aglycons and the picein were either low or negative. These observations indicated that picein is non-limiting for aglycon levels, which may obscure its role in defense against SBW attack.

The trends observed in genetic correlations between the different trait pairs were reflected in estimates of ISE as expected (Lande and Arnold 1983). As a result, selection for resistance biomarkers may influence growth moderately to strongly, which is principally due to the stronger genetic control of resistance biomarkers compared with growth (tree height: $h^{2}=0.40 \pm 0.08$ and $H^{2}=0.16 \pm 0.06$ ). Reduced insect feeding would be expected on trees with high piceol and pungenol levels and this would result in improved fitness. In contrast, a selection for high picein levels may negatively affect growth. From a genetic improvement perspective, our data show that selection of trees with a high level of pungenol could produce indirect genetic gain in tree height owing to ISE of $42 \%$ (progeny trial) and $71 \%$ (clonal trial).

In summary, our results clearly showed that the acetophenone defense traits evaluated here are under strong additive genetic control and suggested that non-additive effects also influence the traits but to a lesser extent. Our findings are consistent with other reports on insect resistance in trees (Kiss and Yanchuck 1991; Alfaro et al. 2004 and Mottet et al. 2015), and thus support the view that the role of additive genetic control in heritable resistance against insects could be an evolutionary driver of chemical diversity in conifers. Many investigations into heritable variation of resistance against herbivores in forest trees have analyzed the damage caused by insects as the main response variable; however, very few have identified or examined the putative mechanism underlying the so-called resistance. The approach we used, based on a quantitative genetic analysis of constitutive resistance biomarkers, has distinct advantages, including avoidance of experimental error that may result when testing interactions between insects and trees; in addition, it may afford future opportunities to discriminate between constitutive and induced defenses, and facilitate studies of resistance trait expression at different stages of phenology and ontogeny. Further research into the resistance traits studied here could target the molecular factors underlying the phenotypic variability in acetophenones, the effects of environmental conditions such as the availability of soil nutrients and the impacts of heritable variation on multi-level trophic interactions in the short and long term.

Acknowledgements We thank the Ministère des Forêts, de la Faune et des Parcs du Québec and JD Irving Ltd for access to field tests, permission to carry out sampling, and use of growth data. We thank Isabelle Giguère and Sébastien Caron (Université Laval) for technical assistance and laboratory support. We thank Gabriel Piette-Lauzière and Gaby Germanos (Université Laval) for assistance during field work and, Karen Guay and Pierre Audet (Université Laval) for assistance in chemical analysis.

Funding Financial support was received from the Fonds de Recherche du Québec-Nature et Technologie (JM, ÉB), from NSERC of Canada for a strategic grant (JM) and INIFAP for supplementary funding for Ph.D. studies (CM-E).

\section{Compliance with ethical standards}

Conflict of interest The authors declare that they have no conflict of interest.

\section{References}

Alfaro RI, VanAkker L, Jaquish B, King J (2004) Weevil resistance of progeny derived from putatively resistant and susceptible interior spruce parents. Ecol Manag 202:369-377

Bahnweg G, Schubert R, Kehr RD, Muller-Starck, Heller W, Langebartels C, Sandermann Jr H (2000) Controlled inoculation of Norway spruce (Picea abies) with Sirococcus conigenus: PCRbased quantification of the pathogen in host tissue and infectionrelated increase of phenolic metabolites. Trees 14:435-441

Beaulieu J, Giguère I, Deslauriers M, Boyle B, MacKay J (2013) Differential gene expression patterns in white spruce newly formed tissue on board the International Space Station. Adv Space Res 52:760-772

Boege K, Marquis RJ (2005) Facing herbivory as you grow up: the ontogeny of resistance in plants. Trends Ecol Evol 20:441-448

Boyle B, Dallaire N, MacKay J (2009) Evaluation of the impact of single nucleotide polymorphisms and primer mismatches on quantitative PCR. BMC Biotechnol 9:75

Chang S, Puryear J, Cairney J (1993) Simple and efficient method for isolating RNA from pine trees. Plant Mol Biol Report 11:113-116

Charmantier A, Garant D (2005) Environmental quality and evolutionary potential: lessons from wild populations. Proc R Soc Lond B Biol Sci 272:1415-1425

Daoust SP, Mader BJ, Bauce E, Despland E, Dussutor A, Albert PJ (2010) Influence of epicuticular-wax composition on the feeding pattern of a phytophagous insect: implications for host resistance. Can Entomol 142:261-270

Delvas N, Bauce É, Labbé C, Ollevier T, Bélanger R (2011) Phenolic compounds that confer resistance to spruce budworm Entomol Exp Appl 141:35-44

Deslauriers A, Caron L, Rossi S (2015) Carbon allocation during defoliation: testing a defense-growth trade-off in balsam fir. Front Plant Sci 13:6 
Falconer DS, MacKay TFC (1996) Introduction to quantitative genetics. 4th edn Longmans Gren, Harlow, Essex, UK

Fine PV, Miller ZJ, Mesones I, Irazuzta S, Appel HM, Stevens MH, Sääksjärvi I, Schultz JC, Coley PD (2006) The growth-defense trade-off and habitat specialization by plants in Amazonian forests Ecol 87:S150-S162

Geber MA, Griffen LR (2003) Inheritance and natural selection on functional traits. Int J Plant Sci 164:S21-S42

Gernandt DS, Willyard A, Syring J, Liston A (2011) The conifers (Pinophyta). In: Plomion C, Bousquet J, Kole C (eds) Genetics, genomics and breeding of conifers. CRC Press, Florida, p 449

Gray DR, Régnière J, Boulet B (2000) Analysis and use of historical patterns of spruce budworm defoliation to forecast outbreak patterns in Quebec. Ecol Manag 127:217-231

Hahn PG, Maron JL (2016) A framework for predicting intraspecific variation in plant defense. Trends Ecol Evol 31:646-656

Hamilton MB (2009). Population genetics. Wiley-Blackwell, West Sussex, UK.

Hansen TF, Pélabon C, Houle D (2011) Heritability is not evolvability. Evol Biol 38:258-277

Harrisson KA, Pavlova A, Telonis-Scott M, Sunnucks P (2014) Using genomics to characterize evolutionary potential for conservation of wild populations Evol Appl 7:1008-1025

Harvey JA, Van Dam N, Gols R (2003) Interactions over four trophic levels: foodplant quality affects development of a hyperparasitoid as mediated through a herbivore and its primary parasitoid. J Anim Ecol 72:520-531

Herms DA, Mattson WJ (1992) The dilemma of plants: to grow or defend. Q Rev Biol 67:283-335

Holland JB (2006) Estimating genotypic correlations and their standard errors using multivariate restricted maximum likelihood estimation with SAS Proc MIXED. Crop Sci 46:642-654

Hoque E (1985) Norway spruce die-back: Occurrence, isolation, biological activity of p-hydroxy acetophenone and p-hydroxy acetophenone-O-glucosidase and their possible roles during stress phenomena. Eur J Pathol 15:129-145

Jardon Y, Morin H, Dutilleul P (2003) Périodicité et synchronisme des épidémies de la tordeuse des bourgeons de l'épinette au Québec. Can J Res 33:1947-1961

King JN, Yanchuk AD, Kiss GK, Alfaro RI (1997) Genetic and phenotypic relationships between weevil (Pissodes strobi) resistance and height growth in spruce populations of British Columbia. Can J Res 27:732-739

Kiss GK, Yanchuck AD (1991) Preliminary evaluation of genetic variation of weevil resistance in interior spruce in British Columbia. Can J Res 21:230-234

Lande R, Arnold S (1983) The measurement of selection on correlated characters. Evolution 37:1210-1226

Leinekugel le Cocq T, Quiring D, Verrez A, Park YS (2005) Genetically based resistance of black spruce (Picea mariana) to the yellowheaded spruce sawfly (Pikonema alaskensis). Ecol Manag 215:84-90

Loehle C (1987) Tree life history strategies: the role of defenses. Can J Res 18:209-222

Lynch M, Walsh B (1998) Genetics and analysis of quantitative traits. 1st edn Sinauer Associates, Sunderland, MA

MacLean DA (1984) Effects of spruce budworm outbreaks on the productivity and stability of balsam fir forests Forest Chron 60:273-279

Mageroy MH, Parent G, Germanos G, Giguère I, Delvas N, Maaroufi H, Bauce É, Bohlmann MJ (2014) Expression of the $\beta$-glucosidase gene Pg $\beta g l u-1$ underpins natural resistance of white spruce against spruce Plant J 81:68-80

Moreira X, Zas R, Sampedro L (2013) Additive genetic variation in resistance traits of an exotic pine species: little evidence for constraints on evolution of resistance against native herbivores. Heredity 110:449-456

Mottet MJ, DeBlois J, Perron M (2015) High genetic variation and moderate to high values for genetic parameters of Picea abies resistance to Pissodes strobi. Tree Genet Genomes 11:58

Obeso JR (2002) The costs of reproduction in plants. New Phytol 155:321-348

Osswald VW, Benz B (1987) P-hydroxyacetophenone and picein contents of healthy and damaged spruce needles from different locations in Bavaria. Eur J Path 19:323-334

Parent GJ, Giguère I, Germanos G, Lamara M, Bauce É, MacKay JJ (2017) Insect herbivory (Choristoneura fumiferana, Tortricidea) underlies tree population structure (Picea glauca, Pinaceae) Sci Rep 7:42273

Pavy N, Boyle B, Nelson C, Paule C, Giguère I, Caron S, Parsons LS, Dallaire N, Bedon F, Bérubé H, Cooke J, Mackay J (2008) Identification of conserved core xylem gene sets: conifer cDNA microarray development, transcript profiling and computational analyses New Phytol 180:766-786

Pearse IS, Baty JH, Herrmann D, Sage R, Koenig WD (2015) Leaf phenology mediates provenance differences in herbivore populations on valley oaks in a common garden. Ecol Entomol 40:525-531

Quiring D, Turgeon J, Simpson D, Smith A (1991) Genetically based differences in susceptibility of white spruce to the spruce bud moth. Can J Res 21:42-47

Rausher MD (2001) Co-evolution and plant resistance to natural enemies. Nature 411:857-864

Reznick D (1985) Cost of reproduction: an evaluation of the empirical evidence. Oikos 44:257-267

Rhoades DF (1979) Evolution of plant chemical defense against herbivores. In: Rosenthal G, Janzen DH (eds) Herbivores: their interaction with secondary plant metabolites. Academic Press, New York and London

Rutledge R, Stewart D (2008) A kinetic-based sigmoidal model for the polymerase chain reaction and its application to high capacity absolute quantitative real-time PCR. BMC Biotech 8:47

Sampedro L, Moreira X, Zas R (2011) Costs of constitutive and herbivore-induced chemical defences in pine trees emerge only under low nutrient availability. J Ecol 99:818-827

Saucier JP, Robitaille A, Grondin P, Bergeron JF, Gosselin J (2011) Les régions écologiques du Québec méridional (4 version). Carte à l'échelle de 1/1 250 000. Ministère des Ressources naturelles et de la Faune du Québec. https://www.mffp.gouv.qc.ca/forets/ inventaire/pdf/carte-regions-ecologiques.pdf

Sgrò CM, Hoffmann AA (2004) Genetic correlations, tradeoffs and environmental variation. Heredity 93:241-248

Squillace AE (1974) Average genetic correlations among offspring from open-pollinated forest trees. Silvae Genet 23:56

Stevens MT, Waller DM, Lindroth RL (2007) Resistance and tolerance in Populus tremuloides: genetic variation, costs and environmental dependency. Evol Ecol 21:829-847

Strauss SY, Agrawal AA (1999) The ecology and evolution of plant tolerance to herbivory. Trends Ecol Evol 14:179-185

Strauss SY, Rudgers JA, Lau JA, Irwin RE (2002) Direct and ecological costs of resistance to herbivory. Trends Ecol Evol 17:278-285

Visscher PM, Hill WG, Wray NR (2008) Heritability in the genomics era-concepts and misconceptions. Nat Rev Genet 9:255-266

Volney WJA, Fleming RA (2007) Spruce budworm (Choristoneura fumiferana spp.) biotype reactions to forest and climate characteristics. Glob Chang Biol 13:1630-1643

Wagner MR, Clancy KM, Tinus RW (1990) Seasonal patterns in the allelochemicals of Pseudotsuga menziesii, Picea engelmanii and Abies concolor. Biochem Syst Ecol 18:215-220 
Walters DR (2011) The evolution of plant defense. In: Plant defense. Warding off attack by pathogens, herbivores and parasitic plants. Wiley-Blackwell, West Sussex, p 236

White TL, Adams WT, Neale DB (2007) Forest genetics. CABI Publishing, Cambridge, MA
Whitham TG, Young WP, Martinsen GD, Gehring CA, Schweitzer JA, Shuster SM (2003) Community and ecosystem genetics: a consequence of the extended phenotype. Ecol $84: 559-573$ 